\title{
Gallstone ileus: a rare surgical emergency
}

\section{Keywords: gallstone, ileus, mechanical bowel}

\section{Introduction}

Gallstone ileus as an uncommon surgical emergency had been defined by Bartholin in the early $17^{\text {th }}$ century as a severe complication of cholelithiasis due to migration of bile stones into intestinal system via fistula between gallbladder, bile duct and duodenum, stomach or colon leading bowel obstruction. ${ }^{1,2}$ Whereas, $80 \%$ of gallstones getting through the intestinum via biliary-enteric fistula did not cause any complication, the rest greater than $2.5 \mathrm{~cm}$ cause mechanical obstruction mostly in terminal ileum in $3 / 4$ of the cases. ${ }^{3-5}$

In the literature, incidence of gallstone ileus had been reported as \%0.3-0.5 of cholelithiasis cases. ${ }^{3}$ Moreover, mortality and morbidity rates would be higher in cases of delay in diagnosis, obesity, old age, and having systemic disorders as diabetes mellitus and cardiovasculary disease. $^{1}$

Hereby, we present a case of gallstone ileus with mechanical bowel obstruction to give awereness and focus on diagnosis and treatment of this rare condition under the current literature.

\section{Case presentation}

65-year-old man was admitted to our emergency department with nausea, vomiting, distension and colicky abdominal pain of 5days' duration. He had regulated hypertension and chronic obstructive pulmonary disease for fifteen years. He had undergone gastric and biliary surgery 25years ago. Physical examination revealed distension and tender abdomen with few poor bowel sounds especially in right mid-lower abdomen. Laboratory tests showed leukocytosis. Plain abdominal X-ray demonstrated the presence of a round hyperdense mass with calcified margins in the right lower quadrant as well as enlarged loops of small bowel (Figure 1) CT scan of the abdomen showed pneumobilia, a calcified mass impacted in the terminal ileum (Figure 2).

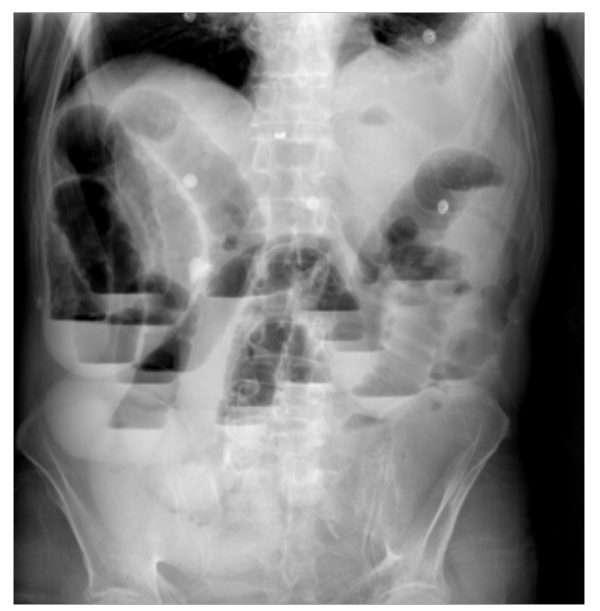

Figure I The plain radiography demonstrated multiple gas and fluid levels in intestines.

\author{
Volume 9 Issue 5 - 2018 \\ Ramazan Serdar Aslan, ' Eray Kara, ${ }^{2}$ Gökhan \\ Pekindil $^{3}$ \\ 'Department of General Surgery, Ușak Banaz State Hospital, \\ Türkiye \\ ${ }^{2}$ Department of General Surgery, University of Manisa Celal \\ Bayar,Türkiye \\ ${ }^{3}$ Department of Radiology, University of Manisa Celal Bayar, \\ Türkiye
}

Correspondence: Eray Kara, FACS, Department of General Surgery, University of Manisa Celal Bayar, Hafsa Sultan Hospital, Manisa, Mithatpașa cd.No:394/5, Çatalkaya apt, Pc 35260, Karataș, İzmir/Türkiye, Tel +90 236 4444228/2326, Fax +90 232 484826I,Email eraykara@hotmail.com

Received: June II, 2018 | Published: September 26, 2018

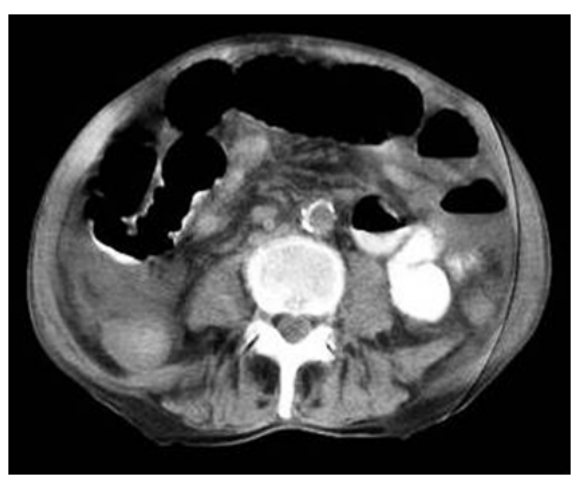

Figure 2 CT scan revealed the opacity in intestinal lumen.

The patient underwent surgical exploration. Preoperatively dilated intestinal loops were found and intraluminal mobile solid mass with $3 \times 4 \times 2 \mathrm{~cm}$ diameter in terminal ileum was observed. A simple enterotomy was performed and the gallstone was removed (Figure 3) (Figure 4). He was discharged on postoperatively $8^{\text {th }}$ day without any complication.

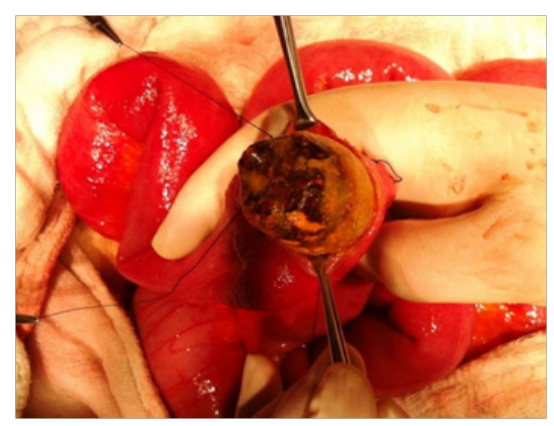

Figure 3 View of the surgically removed gallstone. 


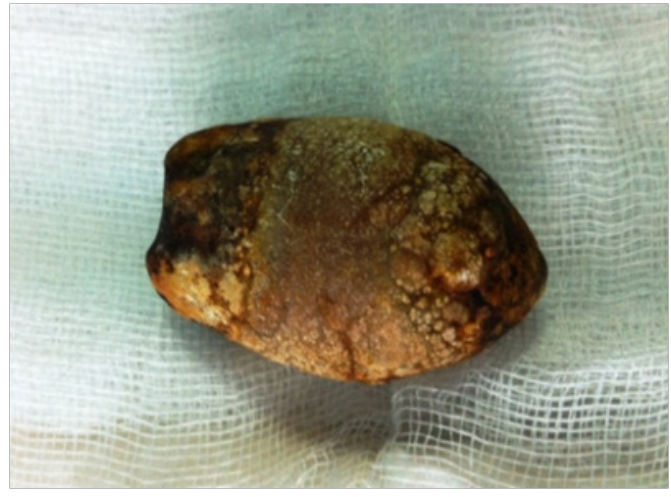

Figure 4 The gallstone.

\section{Discussion}

Gallstone ileus as an unusual complication of cholelithiasis, with $2 \%$ percentage, is the rare cause of mechanical bowel obstruction in the elderly. ${ }^{6}$ Passage of gall-stones into intestinal tractus via biliary enteric fistula is well-known pathologic scenario of the disease. Though the gallstone can impact any part of GI tract, the size of the stone has been reported to be $\leq 2 \mathrm{~cm}$ in diameter to cause mechanical bowel obstruction. ${ }^{7}$ Reisner and Cohen had reported that the most common locations of impaction of gallstone are the terminal ileum and the ileocecal valve because of the anatomical small diameter and less active peristalsis. They also found that the less common locations for impaction are the jejunum, the ligament of Treitz, and the stomach, while the duodenum and colon are the rare locations for impaction. ${ }^{8}$

The clinical symptoms occasionally include nausea, vomiting, pain and hematemesis. Laboratory findings may demostrate impaired liver functions with high bilirubin and alkaline phosphophatase levels etc. The diagnosis is really a challenge for surgeon and usually depends on the radiographic findings. Preoperative conventional diagnostic tools generally do not demonstrate bilioenteric fistula and delay in diagnosis would be inevitable resulting higher morbidity and mortality rates. Whereas radiologic findings of mechanical bowel obstruction can easly be visualized in plane abdominal radiograms and computed tomography, pneumobilia would not be demonstrated in most cases. ${ }^{2,69}$ The classic Rigler's triad of radiography includes mechanical bowel obstruction, pneumobilia, and an ectopic gallstone within bowel lumen. ${ }^{10}$ In our case, abdominal CT scan and plain radiograph also demonstrated dilated intestinal segments with stone opacity and gas in the biliary tree.

Gallstone ileus usually requires emergent surgery to relieve intestinal obstruction. Bowel resection is only indicated when there is intestinal perforation or ischemia. ${ }^{11}$ There is no uniform surgical procedure for this disease because of its low incidence. Although enterolithotomy alone remains the popular operative method in most reports, the one-stage procedure composed of enterolithotomy, cholecystectomy and repair of fistula is necessary, if indicated. ${ }^{12}$ Tan et al. ${ }^{13}$ compared the two surgical strategies of enterolithotomy alone and enterolithotomy with cholecystectomy for the emergent treatment of gallstone ileus, and concluded that both procedures are safe with no mortality, but the better surgical option is enterolithotomy. ${ }^{13}$

Open or laparoscopically surgical exploration of abdomen is the mainstay of the treatment and gall-stone should be removed by enterolithotomy with fistul tract excision if needed and with/without cholecystectomy in cases. Delay of diagnosis, old age, metabolic response to acute disease and current performence of the patient are the factors affecting the decision of one or two step surgery and also the mortality and morbidity rates. We performed surgical remove of gall-stone via enterolithotomy in our case.

In conclusion; gallstone ileus is still a challenging surgical emergency with higher moratlity and morbidity rates for surgeon. It represents less than $1 \%$ of gastrointestinal obstruction cases, with a higher frequency among the elderly. Computed tomography has proven to be the most accurate diagnostic modality, but diagnostic criteria validation is required. Surgical relief of obstruction is the cornerstone of treatment. Given the high incidence of comorbidities in these patients, a good judgement in selecting the surgical procedure is required. Enterolithotomy remains the mainstay of operative treatment. A one-stage cholecystectomy and repair of fistula is justified only in selected patients in good general condition and adequately stabilized preoperatively. ${ }^{14}$

Specific criteria for a one-stage procedure remain to be established. A two-stage surgery is an option for patients with persistent symptomatology after enterolithotomy surgery. Large prospective studies of laparoscopic and endoscopic-guided procedures are expected. ${ }^{14}$ Preoperative diagnosis is often missed or delayed due to current imaging tools. Therefore, it should be kept in mind in differential diagnosis of mechanical bowel obstruction especially in the elderly.

\section{Acknowledgements}

None

\section{Conflict of interest}

The author declares no conflict of interest.

\section{References}

1. Doko M, Zovak M, Kopljar M, et al. Comparison of surgical treatments of gallstone ileus: preliminary report. World J Surg. 2003;27(4):400 404

2. Way LW. Current surgical diagnosis and treatment. Biliary tract. 10th ed. Appleton and Lange. 1994. p. 553-554.

3. Reisner RM, Cohen JR. Gallstone ileus: a review of 1001 reported cases. Am Surg. 1994;60(6):441-446.

4. Kasahara Y, Umemura H, Shiraha S, et al. Gallstone ileus. Review of 112 patients in the japans literature. Am J Surg. 1980;140(3):437-440.

5. Khaira HS, Thomas DR. Gallstone emesis and ileus caused bycommon hepatic duct-duodenal fistula. Br J Surg. 1994;81(5):723.

6. Nakamoto Y, Saga T, Fjishiro S, et al. Gallstone ileus with impaction at the neck of a Meckel's diverticulum. Br J Radiol. 1998;71(852):1320 1322 .

7. Rodríguez Hermosa JI, Codina Cazador A, Gironès Vilà J, et al. Gallstone Ileus: results of analysis of a series of 40 patients. Gastroenterol Hepatol. 2001;24(10):489-494.

8. Reisner RM, Cohen JR. Gallstone ileus: a review of 1001 reported cases Am Surg. 1994;60(6):441-446.

9. Yamada T, Alpers DH, Owyang C, et al. Textbook of gastroenterology. Diseases of the biliary tree-Biliary fistula. JB Lippincott Company; 1991. 
10. Balthazar EJ, Schechter LS. Air in gallbladder: a frequent finding in gallstone ileus. AJR Am J Roentgenol. 1978;131(2):219-222.

11. Syme RG. Management of gallstone ileus. Can J Surg. 1989;32(1):6164.

12. Zuegel N, Hehl A, Lindemann F, et al. Advantages of onestage repair in case of gallstone ileus. Hepatogastroenterology. 1997;44(13):59-62.
13. Tan YM, Wong WK, Ooi LL. A comparison of two surgical strategies for the emergency treatment of gallstone ileus. Singapore Med J. 2004;45(2):69-72.

14. Chou JW, Hsu CH, Liao KF, et al. Gallstone ileus: report of two cases and review of the literature. World J Gastroenterol. 2007;13(8):12951298 . 